\title{
A global perspective on an emotional learning model proposal
}

\author{
Ana Raquel Faria ${ }^{\mathrm{a}}$, Ana Almeida ${ }^{\mathrm{a}}$, Constantino Martins ${ }^{\mathrm{a}}$, Ramiro Gonçalves ${ }^{\mathrm{b}, *}$, José Martins ${ }^{\mathrm{b}}$, \\ Frederico Branco ${ }^{\text {b }}$

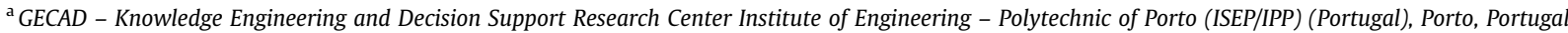 \\ ${ }^{\mathrm{b}}$ INESC TEC and University of Trás-os-Montes e Alto Douro, Vila Real, Portugal
}

\section{A R T I C L E I N F O}

\section{Article history:}

Received 9 May 2016

Received in revised form 15 July 2016

Accepted 10 August 2016

Available online 12 August 2016

\section{Keywords:}

Emotional learning

Learning styles

Emotion recognition

Adaptive learning environments

Affective computing

\begin{abstract}
A B S T R A C T
Existing literature argues that emotions have a significant impact on the majority of human activities and functions. The learning process is one of the activities on which emotions have a direct influence. Thus, understanding the manner in which emotions change the students' learning process is not only very important but it can also allow to improve the existing learning models.

Currently, in the majority of situations, the teacher serves as a facilitator between the student and the learning course, and through a constant analysis of the student's behaviour, emotions and achievements, he constantly performs adjustments to the teaching process in order to meet the students' needs and goals. Thus far, in online learning environments there is no easy way for teachers to analyse students' behaviour and emotions. A possible solution to this problem can be the development of mechanisms that enable computers to automatically detect students' emotions and adapt the learning process in order to meet students' real needs.

An emotional learning model was described and a software prototype was developed and tested, in order to find out whether it performs live identification of the students' emotions, by using affective computing techniques, and whether it automatically performs adjustments to their individual learning process. Through a deeper analysis and multidisciplinary discussion of the achieved results it is possible to acknowledge that not only emotions impact students' learning, but also that an application that performs live emotion recognition and which integrates this feature with adjustable online learning environments will trigger improvements in students' learning.
\end{abstract}

(c) 2016 Elsevier Ltd. All rights reserved.

\section{Introduction}

As indicated by the existing scientific literature, when analysing the learning process one must take into consideration the impact that emotions will have on its success (Kort et al., 2001; Li et al., 2008; Shen et al., 2009). Research on the set of parameters related to online learning, discloses the significance of learners' emotional state and especially the relationship between emotions and affective learning (Kort et al., 2001).

Despite being a debatable topic (Willingham et al., 2015) Coelho et al. (2014) and Javanbakht et al. (2016) argue that emotion plays an important role in the decision process and knowledge acquisition of an individual. Therefore, emotions might

\footnotetext{
* Corresponding author.

E-mail addresses: arf@isep.ipp.pt (A.R. Faria), amn@isep.ipp.pt (A. Almeida), acm@isep.ipp.pt (C. Martins), ramiro@utad.pt (R. Gonçalves), jmartins@utad. pt (J. Martins), fbranco@utad.pt (F. Branco).
} 
influence perception, the learning process, the way people communicate, and the way rational decisions are made. Emotions have two components (Khurana, 2014): the mental component (cognitive) and the physical component (body). They can be classified into categories: primary, secondary and tertiary emotions. Primary emotions occur as a response to some kind of event, which can cause a detectable physical response and trigger emotions such as fear, joy, love, sadness, surprise, anger. From these emotions the other sub-categories can result (Shaver et al., 1987). The studies referring to personality aim at differentiating the people from one another (Santos, 2010). It is acknowledged that personality traits influence people's performance in several life areas (Diseth, 2003; Kumar et al., 2009; Molleman, 2005; Rothmann and Coetzer, 2003). Furthermore, the relationship between personality and learning is largely accepted in existing scientific literature (Busato et al., 1998; Diseth, 2003; Ibrahimoglu et al., 2013). One of the utilised models is the Big Five Model that highlights the existence of the following dimensions: Openness, Conscientiousness, Extraversion, Agreeableness, and Neuroticism (OCEAN) (Komarraju et al., 2009, 2011; Kumar et al., 2009).

A learning style is a method that enables an individual to learn in a personal manner having positive results (Morgan and Baker, 2012). Thus, different people learn in different ways. Everyone has a mix of learning styles, but some people may find out that they have a dominant style of learning. Others may discover that they have a different learning style in different circumstances. There are several models developed by several authors that have tried to represent the way people learn (Morgan and Baker, 2012), such as the Learning Style Inventory (LSI) model (Kolb, 2014), the Felder-Silverman Model (Felder and Silverman, 1988) and also VARK (Fleming and Baume, 2006).

Therefore, the issue debated during this project is the existing gap between a student and his online learning environment. In order to address the referred issue, the research team behind this project developed an architecture and an application prototype aimed at assessing students' emotional state. This was accomplished by using affective computing techniques and developing a proper response to induce a positive stimulus, hence improving the student's learning. As presented in (Faria et al., 2015b) the developed "Emotion Test" prototype was implemented in order to be an engaging learning environment with some multimedia interactions and to be considered an auxiliary learning tool to be used alongside traditional classroom learning.

The present work serves as a detailed analysis for both the proposed architecture and also the prototype implemented to test it. In our opinion, the documentation of all the considerations and conclusions achieved by means of this research project will represent an important contribution to science, given that it will allow other researchers to understand the emotionrelated questions and the impact which this variable might have, in the long run, for the individual learning process.

\section{The Emotion Test Platform}

The Emotion Test simulates the entire learning process, from theoretical explanations to exercises and assessment. Throughout the entire process, the student's emotional state, personality traits and learning preferences are taken into account. The architecture proposed for this prototype is composed of four main models (Faria et al., 2015a): the Student Model, the Emotional Model, the Application Model and the Emotive Pedagogical Model.

The Emotional Interaction Mechanisms are the triggers of an emotional interaction when one captures an emotion that needs to be repressed in order to facilitate the learning process. Emotions to be repressed are: anger, sadness, confusion and disgust. The interaction depends on the student's personality and learning style. Finally, the Graph of Concepts in Case of Failure indicates the steps to be taken when a student fails to pass a subject.

\subsection{System architecture}

The proposed architecture is composed of four major models: the Student Model, the Emotional Model, the Application Model and the Emotive Pedagogical Model.

The architecture is illustrated in Fig. 1.

\subsubsection{The Student Model}

Two different methodologies can be used to implement the Student Model: knowledge based or behaviour based (Kobsa, 1993; Martins et al., 2008). The student model consists in retrieving the student's information and characteristics, including personal information (name, e-mail, telephone, etc.), demographic data (gender, race, age, etc.), knowledge level, limitations, learning styles, emotional profile, personality traits, etc. This information is used to adapt the learning content, the activities and interactions to the students' necessities.

The student model data are collected in different ways. This technique was chosen in order to facilitate the student's progress in the prototype without having the student answer to endless questionnaires. Instead, the questionnaires were chosen taking into consideration the time which was necessary for the student to finish them. Generic information about the students, such as name and email, was retrieved from the University LDAP database and from a small set of questions presented to the student at the beginning of his interaction with the prototype. Other information like personality traits and learning preferences was determined by means of questionnaires which were incorporated in the prototype. Based on Garcia (2012), Saucier and Srivastava (2015) arguments on the reliability of the Big Five Model as a tool for accurately achieving a characterization of an individual personality, this was the chosen tool for the present research project. 


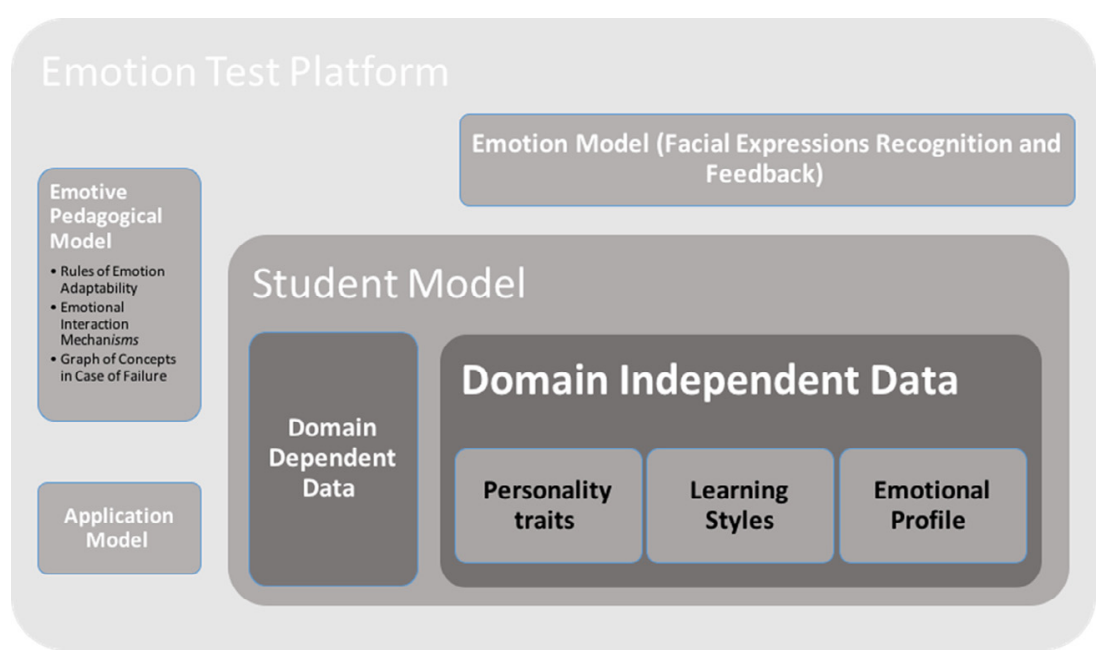

Fig. 1. Proposed Emotion Test Platform architecture.

According to Gosling et al. (2003) and Robins and Trzesniewski (2005), with the Big Five Model five dimensions can be accurately measured by using a more concise set of variables, transposed into reality in a technique named TIPI Questionnaire, which is still able to perform an adequate assessment of the individuals' Openness, Conscientiousness, Extraversion, Agreeableness and Neuroticism. For the scope of the performed research, and assuming the existing time and logistic constraints, the TIPI Questionnaire was chosen as the technique through which students would have their personality characterized. The incorporation of the referred questionnaire in the proposed platform can be observed in Fig. 2.

For the learning preferences, students have to answer the VARK questionnaire. The choice of VARK strategy is due to the fact that it allows to discover the learning preferences in a very simple way. The choice of the learning styles falls in the model proposed by Kolb (2014) that allows great flexibility to implement a solution. The mapping between Kolb's learning styles and the VARK strategy allows the prototype to choose a type of content or activity that will be more appropriate for the student (Martins, 2012). This mapping is shown in Table 1.

2.1.1.1. Stereotypes. The platform's educational activities and emotional interactions are based on the selection of activities which are adapted to the student's profile. Each stereotype has a learning preference, a personality and a type of motivation associated. These stereotypes are shown in the Table 2.

\subsubsection{The Emotion Model}

Emotions have a fundamental role in the learning process as it's shown by several published studies (Kort et al., 2001; Li et al., 2008; Shen et al., 2009).

For this work we considered the hypothesis according to which students' negative emotions have negative effects on their behaviour, attention, motivation and finally on the learning process results. On the other hand, positive emotions would be helpful for the learning process. This hypothesis is corroborated by some previous studies (Kort et al., 2001; Stafford, 2004; Um et al., 2007). Another hypothesis was made concerning the influence of the students' learning preferences and personality on their learning process. This hypothesis was also recognized in previous studies (Fleming and Baume, 2006; Ibrahimoglu et al., 2013; Komarraju et al., 2011; Morgan and Baker, 2012).

The proposed Emotion Model is composed of two sub-models, Facial Expression Recognition that deals with capturing the emotion and other features and the Feedback Model that tries to access the students' impression and feelings after using the prototype.

Facial Expression Recognition allows the video analysis of images in order to recognise an emotion. This type of emotion recognition was chosen because it was the least intrusive during the students' activities. The emotion recognition is achieved by making use of an API entitled ReKognition (Orbe.us, 2015). This API allows the detection of the face, eyes, nose and mouth and it can also observe whether the eyes and mouth are open or close. In addition, it specifies the gender of the individual and gives an estimate of age and emotion. Every moment a group of three emotions is captured. For each emotion a number is given that shows the confidence level of the emotion which was captured.

For each set of three emotions there are two possible situations:

1. One of the emotions has the percentage of level confidence higher than $85 \%$. In this case the emotion is considered a prevalent emotion;

2. The two emotions with the highest percentage of level confidence are matched to produce primary, secondary or tertiary dyads. 


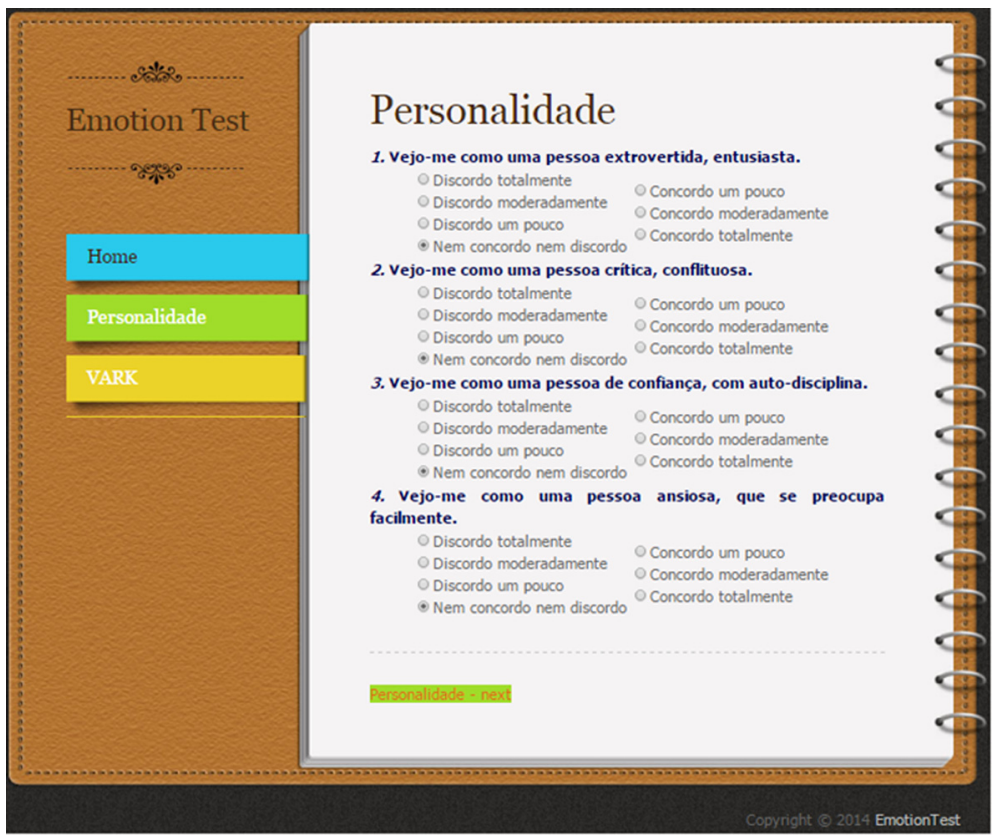

Fig. 2. Emotion Test - TIPI questionnaire.

\section{Table 1}

Mapping of Kolb's Learning Styles and VARK Learning Preferences. Adapted from (Martins, 2012).

\begin{tabular}{ll}
\hline Kolb's Learning styles & VARK \\
\hline Feel and see & Visual \\
Hear and think & Aural \\
Doing and thinking & Kinetic \\
Do and feel & Kinetic \\
\hline
\end{tabular}

Table 2

Stereotypes used to support our research.

\begin{tabular}{|c|c|c|c|}
\hline Stereotype & Learning preference & Personality & Motivation \\
\hline SVO & Visual & \multirow{4}{*}{ Openness } & Achievement \\
\hline SAO & Aural & & Intrinsic motivation \\
\hline SRO & Read/write & & \\
\hline SKO & Kinetic & & \\
\hline SVC & Visual & \multirow[t]{4}{*}{ Conscientiousness } & \multirow[t]{4}{*}{ Intrinsic and Extrinsic motivation } \\
\hline SAC & Aural & & \\
\hline SRC & Read/write & & \\
\hline SKC & Kinetic & & \\
\hline SVE & Visual & \multirow[t]{4}{*}{ Extraversion } & \multirow[t]{4}{*}{ Extrinsic motivation } \\
\hline SAE & Aural & & \\
\hline SRE & Read/write & & \\
\hline SKE & Kinetic & & \\
\hline SVA & Visual & \multirow[t]{4}{*}{ Agreeableness } & \multirow[t]{4}{*}{ Achievement } \\
\hline SAA & Aural & & \\
\hline SRA & Read/write & & \\
\hline SKA & Kinetic & & \\
\hline SVN & Visual & \multirow[t]{5}{*}{ Neuroticism } & \multirow[t]{5}{*}{ Motivation } \\
\hline SAN & Aural & & \\
\hline SRN & Read/write & & \\
\hline SKN & Kinetic & & \\
\hline Neutral & & & \\
\hline
\end{tabular}




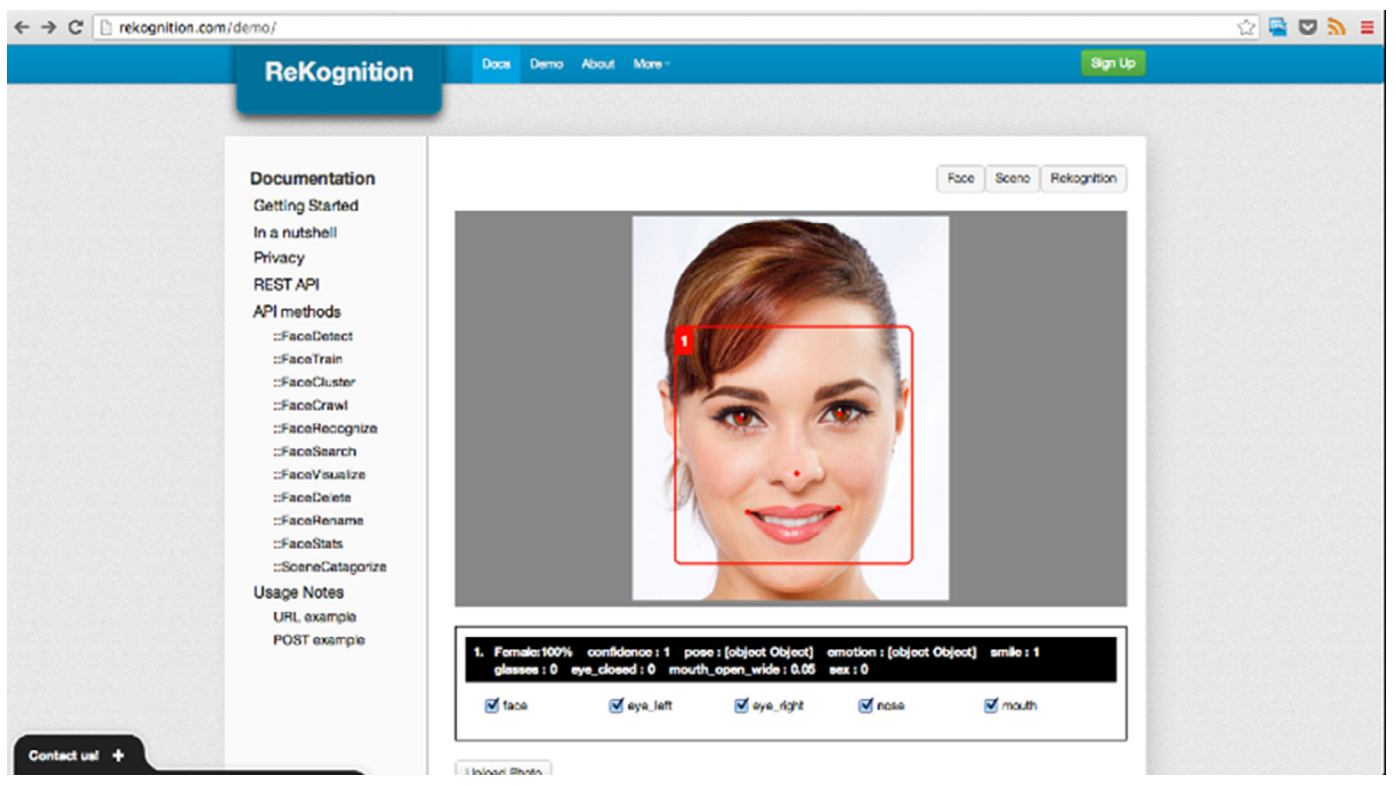

Fig. 3. ReKognition API demo application.

As one can perceive in Fig. 3, ReKognition is able to detect seven emotions, namely happiness, sadness, anger, disgust, surprise, confusion and calmness. In the prototype developed to capture emotions a live video feed (using a webcam) was included in order not only to film students but also to take individual photos every $20 \mathrm{~s}$ (used to run emotional analysis). This procedure allows to reach the data necessary to identify the students' emotions. Considering the existence of security concerns associated with using live video feeds, particularly those based on online data transfers, an extra effort was made to address these security and privacy issues. The security problems were, to some extent, solved by using Hypertext Transfer Protocol Secure (HTTPS) which is a communication protocol for secure communication over the internet (Clark and van Oorschot, 2013). The use of this protocol also solved the problem of privacy, but the user needed to grant access at least once so that the browser would remember the user's choice. Although this seemed to solve one problem, it created another. If the user fails to grant access to the webcam in the beginning of the prototype use, the capturing of the user's emotion would not work properly and, consequently, the developed prototype would not adapt the course to the student's emotions.

Feedback consists in asking the student's opinion about the course he has taken with questions like (Faria et al., 2015a):

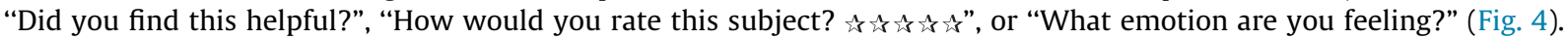

\subsubsection{The Application model}

The application model is composed of a set of modules containing different subjects. Each subject is made up of a number of steps that the student has to pass in order to complete his learning program. Not all program steps are mandatory, hence the execution of all the optional steps depends on the students' will.

2.1.3.1. Concepts Graph. The concepts graph consists of four steps: The Placement Test (PT), the Subject Content and Subject Exercises (SC) and the Subject Test (ST). The PT is optional and allows the application to access the initial knowledge level of the student. SC contains the detailed explanation of the subject and is followed by SE that consists of exercises which will allow students to get the necessary points (80\%) to become eligible for taking the referred subject final test (Faria et al., 2015b). This sequence of steps and requirements is represented in both Figs. 5 and 6 .

Even though the first step of the subject's program (placement test) is optional, this is designed to give students and teachers a quick (and comprehensively less accurate) way of assessing students' knowledge level. The $\mathbf{P T}$ result $\mathbf{P T}_{\mathrm{s}}$ percentage that is added to the student's knowledge item $\left(\mathrm{K}_{\mathrm{s}}\right)$, on a particular subject, and places the student at one of the five levels of knowledge $k p t=\sum_{i=0}^{5}$ exercise $_{i}$. If the $\mathbf{P T}$ is not performed $\mathbf{K}_{\mathbf{s p}}$ will be equal to zero and the student will start the program without having a known level of knowledge.

The Subject Content (SC) contains explanations about the subject. The subject explanation depends on the stereotype (which is based on the Student Model and the combination of his learning styles, personality dimensions and motivations). Each explanation will have a practice exercise. These exercises will allow the students to obtain points to perform the final test of the subject. The student needs to get $80 \%$ on the TotalK $\mathbf{K}_{\mathbf{s c}}$ to take the subject test.

The Subject Test (ST) is the assessment of the learned subject. This will give a final value $\mathbf{k}_{\mathbf{s t}}$ that represents the student's knowledge on the subject, $k s t=\sum_{i=0}^{5}$ exercise $_{i}$. Only if the $\mathbf{k}_{\mathbf{s t}}$ is higher than $50 \%$ it can be concluded that the student has 


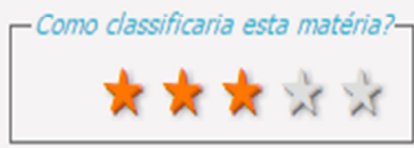

Fig. 4. Emotion Test - Feedback.

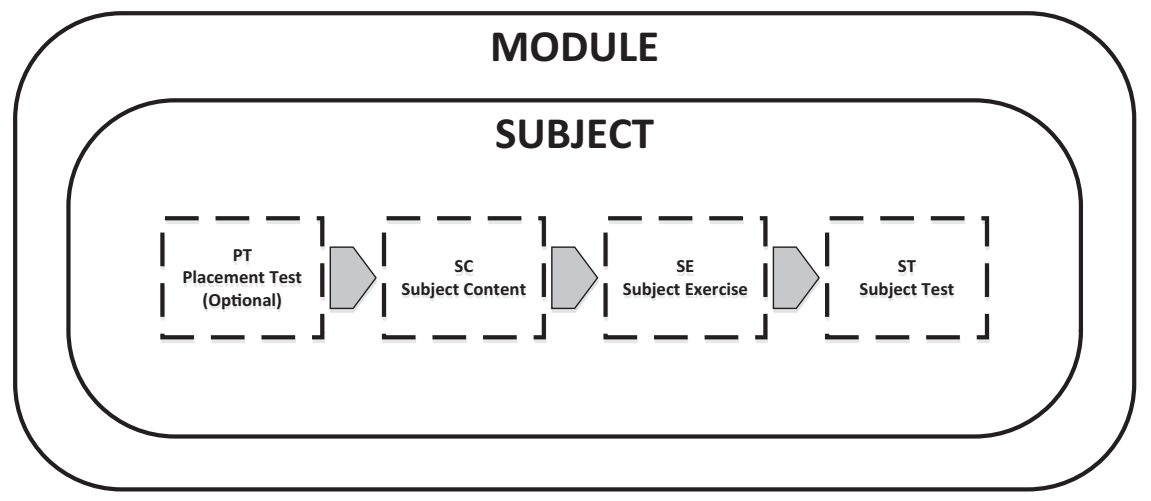

Fig. 5. Concepts Graph. Adapted from (Faria et al., 2015b).

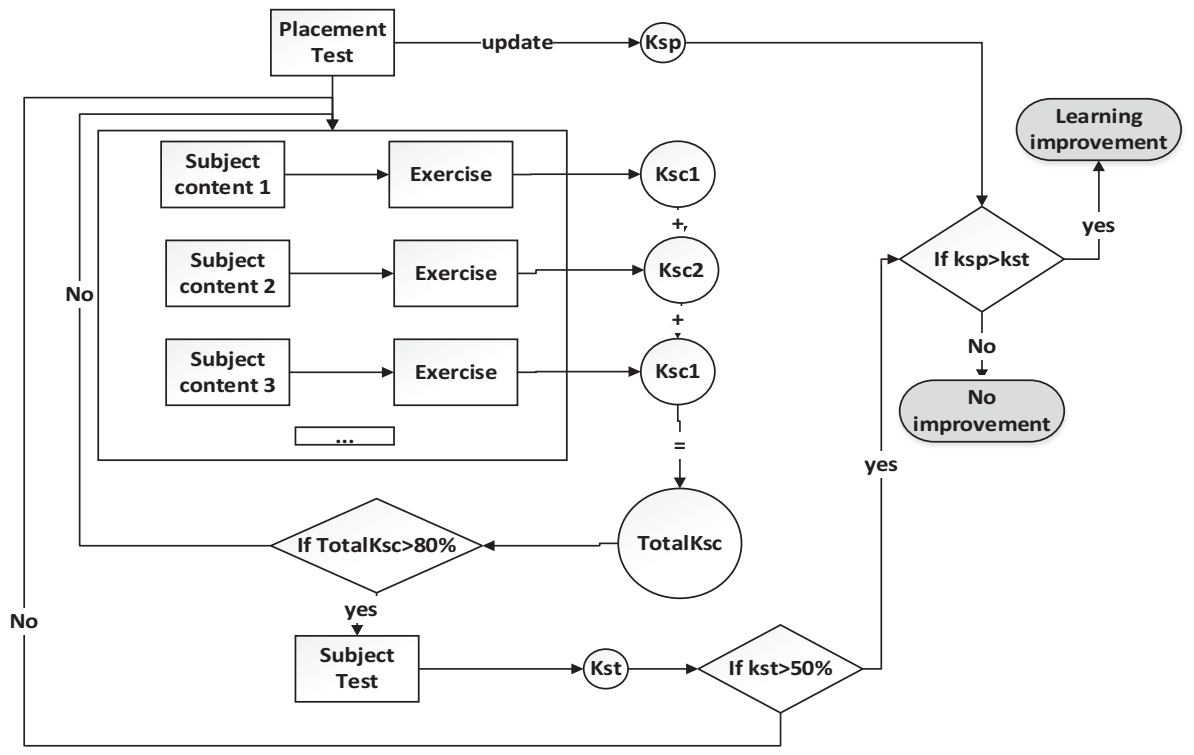

Fig. 6. Representation diagram.

successfully completed the subject. In this case the values of $\mathbf{k}_{\mathbf{s p}}$ and $\mathbf{k}_{\mathbf{s t}}$ are compared to verify if there was an effective improvement on students' knowledge.

The above-mentioned sequence is visually represented in Fig. 6.

2.1.3.2. Subjects. The domain used for the prototype evaluation is Numerical conversion. Within this domain, the subject is the conversion of decimal numbers to another base (binary, octal and hexadecimal) with the following points (Fig. 7):

Subject 1 - Conversion decimal to a different base Program

A1 - Placement Test

o small 5 questions test, with random questions from B2, C2 and D2, to grade the initial knowledge of the student;

B1 - Decimal to binary

o Explanation about how to convert numbers from decimal to binary;

B2 - Decimal to binary exercises

C1 - Decimal to Octal

o Explanation about how to convert numbers from decimal to octal; 


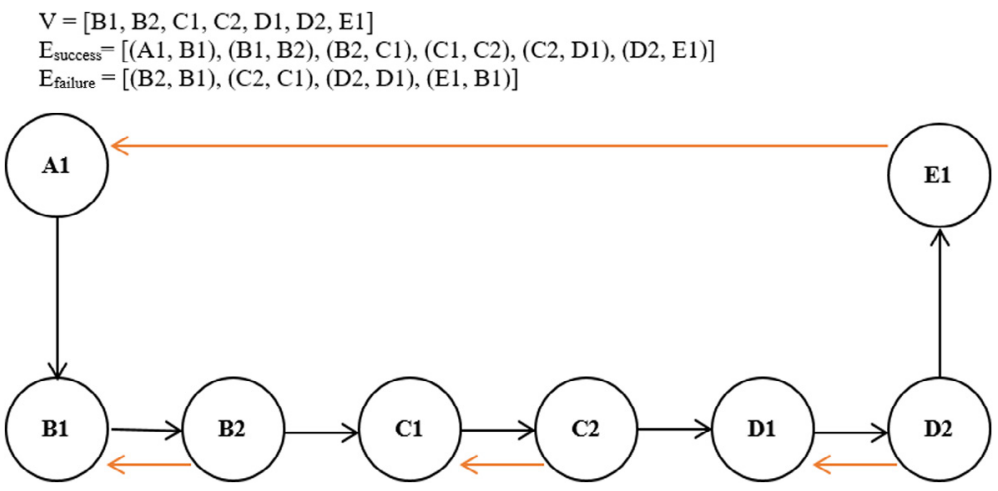

Fig. 7. Graph of concepts path and failure.

Table 3

Stereotype emotions.

\begin{tabular}{llll}
\hline Stereotype & Expected emotion & Emotions that can positively influence learning & Emotions that can trigger an interaction \\
\hline SVO & Anticipation & Calmness/Serenity & Anger \\
SAO & Interests & Happiness & Confusion \\
SRO & Optimism & Surprise & Disgust \\
SKO & Calmness/Serenity & Calmness/Serenity & \\
SVC & & & \\
SAC & & & \\
SRC & Calmness/Serenity & \\
SKC & Joy/Happiness & Happiness & \\
SVE & Ecstasy & & \\
SAE & & Calmness/Serenity & \\
SRE & Trust & Happiness & \\
SKE & Submission & & \\
SVA & cHappiness & Calmness/Serenity & \\
SAA & Anger & & \\
SRA & Contempt & & \\
SKA & Anxiety & & \\
SVN & & & \\
SAN & & & \\
SRN & & & \\
SKN & & & \\
\hline
\end{tabular}

C2 - Decimal to Octal exercises

D1 - Decimal to hexadecimal

o Explanation about how to convert numbers from decimal to hexadecimal;

D2 - Decimal to hexadecimal exercises

E1 - Subject Test

o Similarly, to the placement test, this helps at grading the final knowledge of the student.

The students start by taking a placement test (A1) followed by the introduction of the conversion from decimal to binary (B1). The explanation takes into account the learning preferences and personality of the student. After the completion of the explanation about the conversion from decimal to binary this is followed by the subject exercises (B2). If the students are able to complete the exercises a new subject is presented. First, the conversion from decimal to octal is introduced (C1) and after that the conversion from decimal to hexadecimal (D1). Moreover, both explanations are followed by the subject exercises (C2) and (D2). If the student completes all the subject's explanations and exercises he has to perform the subject test (E1).

\subsubsection{The Emotive Pedagogical Model}

The Emotive Pedagogical Model contains three sub-models: Rules of Emotion Adaptability, Emotional Interaction Mechanisms and Graph of Concepts in case of failure. In each phase the student's emotional profile is updated with the help of the facial expression recognition software. The emotional expression allows the creation of an emotional profile and with this information it is possible to make some adjustments to the content of the application or trigger an emotional motivation action or an emotional interaction.

The Rules of Emotion Adaptability manage the way the subject content is presented. The subject content is presented according to the student's learning preferences and personality. In this way information and exercises are presented in a 
Table 4

Emotions that can trigger an interaction.

\begin{tabular}{|c|c|c|}
\hline \multirow[t]{2}{*}{ Stereotype } & Emotions that can trigger an interaction & \multirow[t]{2}{*}{ Emotions required } \\
\hline & Confusion & \\
\hline SVO & $\begin{array}{l}\text { Happiness can be triggered by showing images or playing sounds that can remind of } \\
\text { happy things like comedies or upbeat music }\end{array}$ & $\begin{array}{l}\text { Calm/Serenity } \\
\text { Happiness }\end{array}$ \\
\hline SAO & $\begin{array}{l}\text { Happiness can be triggered by playing sounds that can remind of happy things like } \\
\text { comedies or upbeat music }\end{array}$ & Surprise \\
\hline SRO & $\begin{array}{l}\text { Another trigger for happiness is the written word. Reading phrases that contain } \\
\text { words such as 'new', 'exciting' and 'wonderful' will trigger a good sensation }\end{array}$ & \\
\hline SKO & $\begin{array}{l}\text { Happiness can also be triggered by a positive experience such as receiving good news } \\
\text { or achieving a goal }\end{array}$ & \\
\hline SVC & $\begin{array}{l}\text { Happiness can be triggered by showing images or playing sounds that can remind of } \\
\text { happy things like comedies or upbeat music }\end{array}$ & \\
\hline SAC & $\begin{array}{l}\text { Happiness can be triggered by playing sounds that can remind of happy things like } \\
\text { comedies or upbeat music }\end{array}$ & \\
\hline SRC & $\begin{array}{l}\text { Another trigger for happiness is the written word. Reading phrases that contain } \\
\text { words such as 'new', 'exciting' and 'wonderful' will trigger a good sensation }\end{array}$ & \\
\hline SKC & $\begin{array}{l}\text { Happiness can also be triggered by a positive experience such as receiving good news } \\
\text { or achieving a goal }\end{array}$ & \\
\hline SVE & $\begin{array}{l}\text { Happiness can be triggered by showing images or playing sounds that can remind of } \\
\text { happy things like comedies or upbeat music }\end{array}$ & \\
\hline SAE & $\begin{array}{l}\text { Happiness can be triggered by playing sounds that can remind of happy things like } \\
\text { comedies or upbeat music }\end{array}$ & \\
\hline SRE & $\begin{array}{l}\text { Another trigger for happiness is the written word. Reading phrases that contain } \\
\text { words such as 'new', 'exciting' and 'wonderful' will trigger a good sensation }\end{array}$ & \\
\hline SKE & $\begin{array}{l}\text { Happiness can also be triggered by a positive experience such as receiving good news } \\
\text { or achieving a goal }\end{array}$ & \\
\hline SVA & $\begin{array}{l}\text { Happiness can be triggered by showing images or playing sounds that can remind of } \\
\text { happy things like comedies or upbeat music }\end{array}$ & \\
\hline SAA & $\begin{array}{l}\text { Happiness can be triggered by playing sounds that can remind of happy things like } \\
\text { comedies or upbeat music }\end{array}$ & \\
\hline SRA & $\begin{array}{l}\text { Another trigger for happiness is the written word. Reading phrases that contain } \\
\text { words such as 'new', 'exciting' and 'wonderful' will trigger a good sensation }\end{array}$ & \\
\hline SKA & $\begin{array}{l}\text { Happiness can also be triggered by a positive experience such as receiving good news } \\
\text { or achieving a goal }\end{array}$ & \\
\hline SVN & $\begin{array}{l}\text { Happiness can be triggered by showing images or playing sounds that can remind of } \\
\text { happy things like comedies or upbeat music. Also calm images of landscapes can } \\
\text { soothe a person }\end{array}$ & \\
\hline SAN & $\begin{array}{l}\text { Happiness can be triggered by playing sounds that can remind of happy things like } \\
\text { comedies or upbeat music }\end{array}$ & \\
\hline SRN & $\begin{array}{l}\text { Another trigger for happiness is the written word. Reading phrases that contain } \\
\text { words such as 'new', 'exciting' and 'wonderful' will trigger a good sensation. Also } \\
\text { using words that can calm, repeating gentle phrases like "relax", "calm down" or } \\
\text { "take it easy" }\end{array}$ & \\
\hline SKN & $\begin{array}{l}\text { Happiness can also be triggered by a positive experience such as receiving good news } \\
\text { or achieving a goal }\end{array}$ & \\
\hline
\end{tabular}

more agreeable manner to the student, helping him to comprehend the subject easily. For each stereotype the information is presented in a different way.

2.1.4.1. Emotional Interaction Mechanisms. For all the stereotypes there is an emotion or group of emotions that is expected to be found due to the student's personality (Shiota et al., 2006). These emotions can have a positive or a negative influence on the learning process. The Emotional Interaction Mechanism aims at bringing the students back to the emotions that influence the learning process in a positive way, when a trigger situation arises. As perceivable in Table 3, the relation between stereotypes can be noticed, the expected emotion(s), the emotions that can positively influence learning, and the emotions that can trigger an interaction by the prototype.

The emotions to be repressed are: anger, sadness, confusion and disgust. The interaction can depend on the personality and on the learning preferences of the student. In Table 4 it can be noticed which emotions can trigger an interaction and which could be a possible interaction, for each stereotype, to change an emotion.

To interact with the students a virtual character was created. The virtual character was created using Voki ${ }^{1}$. It was named Yoshi and it is one of the free avatars provided by Voki. The character which was created performs all the emotional interactions carried out on the prototype. The same character is used in all the emotional interactions for all the stereotypes. Yoshi's main purpose is to keep the students engaged in the learning process. Yoshi's actions depend on the student's personality and learning preferences. Each personality has an expected emotion (Shiota et al., 2006) and these emotions, that can be positive

1 http://www.voki.com/ 
or negative, influence the learning process. The objective is to foster the positive emotions and try to suppress the negative emotions (Shen et al., 2009).

The graph of concepts in case of failure represents the steps to be taken when someone fails passing a subject. To be approved in a subject all the tasks must be completed, and only when a subject has been completed it is possible to pass to the next one.

With a subject the student has to complete the placement test, the subject content plus exercises with a grade equal or higher than $80 \%$ and the subject test by approval with a grade higher than $50 \%$ in order to complete the subject. In case of failure the student has to go back to the subject content and repeat all the steps. The following directed acyclic graph G2(V, E) represents the complete graph of paths in case of failure. In which V: is the set of vertices (or nodes) and $\mathrm{E}$ : is the set of ordered pairs of vertices, called paths.

\section{Results analysis}

The research work was based on the principle according to which emotions can influence several aspects of people's lives. Emotions can affect decision processes and knowledge acquisition of an individual because they directly influence the perception, the learning process, the way people communicate and the way rational decisions are made. Given the fact that on a learning platform there isn't any mechanism able to perceive any changes in the emotional behaviour and intervene in order to recapture the student's attention and motivation, similar to the role of the teacher in a traditional classroom, a question was asked: what if a learning platform had a mechanism that could detect a student's emotional behaviour and interact with him accordingly taking his profile as basis? Could this influence or even improve the student's learning results? Considering all of the above, the goal of the research is to find out if a learning platform taking into account the emotional profile of a student can produce better learning results than a learning platform with no emotional interaction. A prototype was developed to test the assumption made. This prototype takes into account the student's personality, learning styles and the emotional profile.

\subsection{Participants}

To evaluate the prototype some tests were conducted with students from Instituto Superior de Engenharia do Porto (ISEP) enrolled in two Engineering courses: Informatics Engineering and Systems Engineering. One hundred and fifteen students, aged between 17 and 42 years old (20\% females and $80 \%$ males) and primarily living in the north region of Portugal, participated in the tests inherent to the present research.

These students were chosen because during their course one of the approached subjects is decimal conversion to other bases and it is an important knowledge foundation for other subjects in their course. It was also attempted to conduct these experiences before this subject was addressed in their classes, so the students did not have any prior knowledge of the subject.

\subsection{Method}

To evaluate the prototype, two pre-tests and a final test were conducted. For the first pre-test the students were grouped randomly in 2 groups: Group v1 - Test the prototype with the emotional interaction and learning style with a high level of difficulty and Group v2 - Test the prototype without the emotional interaction and learning style with a high level of difficulty.

Group v1 complete the following tasks:

1. A diagnostic test (in paper) to help grade the student initial knowledge level.

2. The evaluation of the prototype with the emotional interaction and learning style. This would include, the login into the prototype, at this moment the initial data for the student model begins to be collected. By accessing the school's Lightweight Directory Access Protocol (LDAP) one was able to gather the generic information of the students (like name, email and other).

3. The answer of two questionnaires (TIPI, VARK). This allows the prototype to known the student's personality traits and learning preferences.

4. In this point the student can assess the learning materials and exercises. From the moment the student login his emotion state has been monitor and saved and every time that is detected an emotion that triggers an intervention it would appear on the screen.

5. The student has to complete a final test (in paper) to help grade the student final knowledge level.

6. The answer of the Acceptability questionnaire to determine the prototype acceptability.

Group v2 had to follow the same method, but with one difference. Even though the emotional state is monitor, when is detected an emotion that triggers an intervention it would not appear on the screen (point 4 of the method). 
Table 5

Tests results.

\begin{tabular}{|c|c|c|c|c|c|c|c|c|c|}
\hline & Groups & & $\mathrm{N}$ & Minimum & Maximum & Mean & Std. Deviation & Mann-Whitney U & $\mathrm{P}$ \\
\hline \multirow[t]{4}{*}{ 1st pre-test } & Group v1 & Diagnostic Test in paper & 31 & 0 & 100 & $12.26 \%$ & 22,9 & 472,5 & 0890 \\
\hline & Group v2 & Diagnostic Test in paper & 31 & 0 & 60 & $11,61 \%$ & 20,5 & & \\
\hline & Group v1 & Final Test in paper & 31 & 0 & 100 & $36,00 \%$ & 36,5 & 452,5 & 0851 \\
\hline & Group v2 & Final Test in paper & 31 & 0 & 100 & $34,19 \%$ & 34,7 & & \\
\hline \multirow[t]{4}{*}{ 2nd pre-test } & Group v3 & Diagnostic Test in paper & 14 & 0 & 80 & $28,57 \%$ & 37,4 & 51,5 & 0146 \\
\hline & Group v4 & Diagnostic Test in paper & 11 & 0 & 100 & $49,09 \%$ & 36,2 & & \\
\hline & Group v3 & Final Test in paper & 14 & 0 & 100 & $67,14 \%$ & 33,8 & 66,5 & 0554 \\
\hline & Group v4 & Final Test in paper & 11 & 0 & 100 & $56,36 \%$ & 39,8 & & \\
\hline \multirow[t]{4}{*}{ Final Test } & Group v3 & Diagnostic Test in paper & 14 & 0 & 100 & $45,70 \%$ & 40,3 & 83 & 0479 \\
\hline & Group v4 & Diagnostic Test in paper & 14 & 0 & 80 & $37,10 \%$ & 29,2 & & \\
\hline & Group v3 & Final Test in paper & 14 & 60 & 100 & $85,70 \%$ & 12,2 & 54 & 0029 \\
\hline & Group v4 & Final Test in paper & 14 & 0 & 100 & $61,40 \%$ & 33,7 & & \\
\hline
\end{tabular}

Due to limitations of the students' timetable, each group only had one hour to conduct the pre-test, this proved to be inefficient because the students didn't have enough time to complete the required tasks. Also, it was observed that due to the high level of difficulty of the application (80\% to pass to the next task), some students didn't get that grade and had to start again, this proved to lead the students to frustration and to give up the completion of the group task. Another problem was the capture of emotion that sometimes did not work properly. For these reasons was conducted a second pre-test. The same evaluation protocol was used for Groups v1 and v2, but with a time increase, roughly 1 and half hours. Also, the prototype level of difficulty was cut by half. This second pre-test was not performed by the same students. These changes originated Groups v3 - Test the prototype with the emotional interaction and learning style with a low level of difficulty and Groups v4 - Test the prototype without the emotional interaction and learning style with a low level of difficulty.

The first and second pre-test were made by the students of Informatics Engineering. For the final test, the experience was repeated with the students of Systems Engineering course, but only were tested groups v3 and v4 with a time increase, two hours to conduct the test.

All data gathered was processed by Statistical Package for Social Sciences (SPSS) in order to statistically analyze the data (Table 5).

As data does not have a normal distribution, the two pairs of groups were compared using a non-parametric test MannWhitney. For group v1, diagnostic test has a mean of $12,26 \%$ (Standard Deviation (SD) $=22,9$ ) and the final test a mean of $36,00 \%(S D=36,5)$. For group v2 diagnostic test has a mean of $11,61 \%(S D=20,5)$ and the final test a mean of $34,19 \%$ $(\mathrm{SD}=34,7)$. The observed dissimilarities between these two groups are not statistically significant, not only for the diagnostic test but also for the final test. The diagnostic test has a Mann-Whitney $\boldsymbol{U}=472,5$ for the same sample size in both groups of 31 students with $\boldsymbol{P}=0,890$. The final test has a Mann-Whitney $\boldsymbol{U}=452,5$ for the same sample size in both groups of 31 students with $\boldsymbol{P}=0,851$. As the $\boldsymbol{P}$ value is in both analyses is higher than 0,050 it can be concluded that the differences between the groups are not statistically significant. For group v3 diagnostic test has a mean of $28,57 \%(S D=37,4)$ and the final test a mean of $67,14 \%$ ( $S D=36,2$ ). For group v4 diagnostic test has a mean of $49,09 \%(S D=36,2)$ and the final test a mean of $56,36 \%$ $(\mathrm{SD}=39,8)$. The observed differences between these two groups also are not statistically significant. The diagnostic test has a Mann-Whitney $U=51,5$ and for a sample size for group v3 of 14 students and for group v4 of 11 students. For this sample it was found a $\boldsymbol{P}$ value of 0,146 . The final test has a Mann-Whitney $\boldsymbol{U}=66,5$ and for an equal sample size of the diagnostic test. For this analysis it was found a $\boldsymbol{P}$ value of 0,554. As the previous test it has a $\boldsymbol{P}$ value higher than 0,050 this indicates that the differences between the groups are not statistically significant.

These two pre-tests were important to calibrate the final test and to help us understand the basic requirements of the experience such as time and difficulty.

For the final group v3, the diagnostic test has a mean of $45,7 \%(S D=40,3)$ and the final test a mean of $85,7 \%(S D=12,2)$. For group v4, the diagnostic test has a mean of $37,1 \%(S D=29,2)$ and the final test a mean of $61,4 \%(S D=33,7)$. The diagnostic test has a Mann-Whitney $\boldsymbol{U}=83,0$ and for a sample size of 14 students. For this study it was found a $\boldsymbol{P}$ value of 0,479 which shows that it doesn't have any statistical difference which is comprehensible because it was assumed that all students had more or less the same level of knowledge. The final test it has a Mann-Whitney $\boldsymbol{U}=54,0$ and for an equal sample size of the diagnostic test. For this analysis it was found a $\boldsymbol{P}$ value of 0,029 in this sample the differences observed are statistical different. This can be a good indicator that the group that had emotional assistance had the higher learning results, but this assumption must be confirmed as evidence.

Using the two-way ANOVA a test was preformed concerning the emotional state of the student during this experiment. The assumption was that the student in a negative state throughout the experiment had lower results. The differences found were statistically significant $(P=0,011)$. Consequently, this can indicate that the emotional state could have influenced in the final test results of the students. Fig. 8 presents the results collected.

In addition, a series of tests were made to compare the means values of the students by group and by learning preference, by group and personality. The objective of running these tests was to find out if learning preference and personality had any influence on the outcome of the final test. In this two tests, by learning preference and by personality, no statistically 


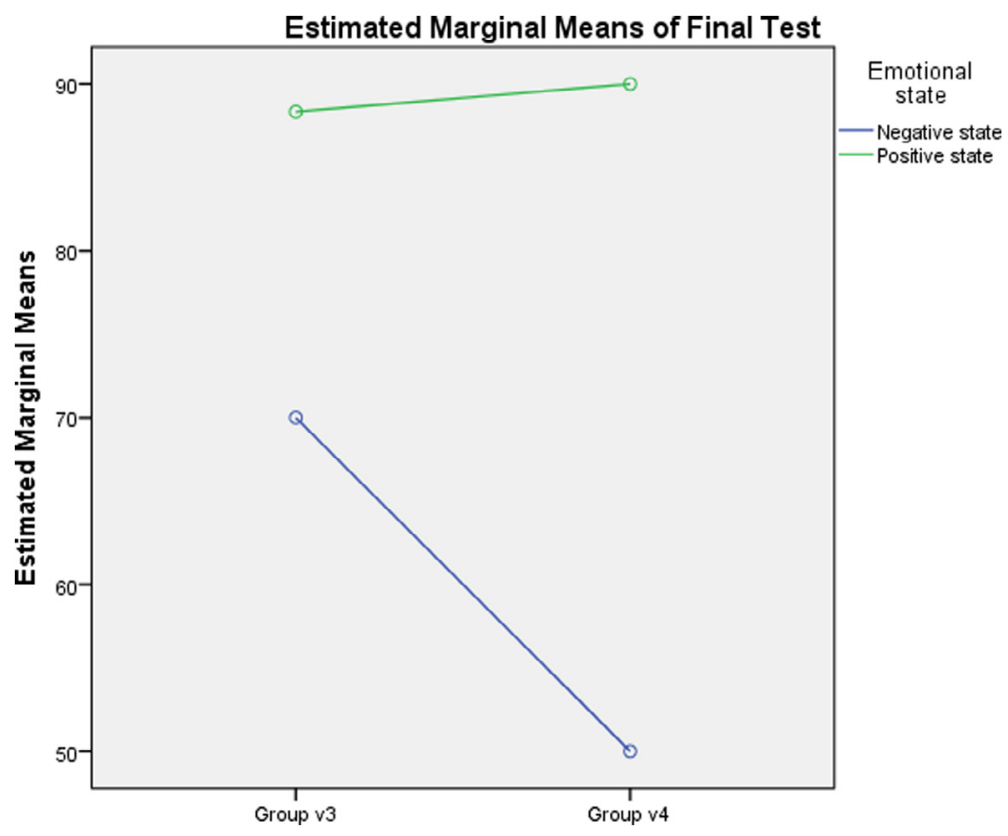

Fig. 8. Estimated Marginal Means of the Final Test - Emotional State.

significant differences were found in the data. Therefore, it cannot be concluded that learning preference and personality in each group had any influence in the final test outcome. To prove this assumption, it is needed a larger sample size.

\subsubsection{Results of Acceptability Survey}

The assessment questionnaires had the purpose of assessing students' opinion on the proposed Emotion Test Platform, particularly its adequacy, usability and acceptance. In order to perform the referred assessment a set of questionnaires were defined and all questions were designed to be measured by a 4-point Likert scale. The integrity of each survey was determined by means of the Alpha reliability coefficient Cronbach (Woodward and Chambers, 1983).

With regard to the first questionnaire, which evaluates the acceptance of the platform, the value of Cronbach's Alpha was 0.934. On the other hand, for the usefulness and the difficulty of the questionnaire the Cronbach's alpha coefficient was at 0.953 and 0.949 , respectively. With these values, it can be stated that the internal consistency of the survey is very good (Table 6).

The Emotion test platform's usefulness in helping students to learn outside the classroom was determined with the following affirmation: "The application would facilitate the study of the subject outside the classroom". The analysis of the options chosen by the students showed that $83.8 \%$ of the students agree with this affirmation.

Regarding the usability questionnaire, the following set of items were used: (1) "The application information is well organized"; (2) "The application has good graphics/design"; (3) "It's easy to access activities/tasks"; and (4) "Can you easily access the content in the application for the subject and therefore can you easily access the activities of the application and the interaction is given by the application useful". The analysis of the referred questionnaire results showed that more than $80 \%$ of the students have classified the items with more positive scale values (Table 7).

Table 6

Questionnaire Results Distribution.

\begin{tabular}{|c|c|c|c|c|c|}
\hline & Fully Disagree & Disagree & Agree & Fully Agree & No opinion \\
\hline 1. The application would facilitate the study of the discipline outside the classroom. & $3,2 \%$ & $3,2 \%$ & $54,8 \%$ & $29,0 \%$ & $9,8 \%$ \\
\hline 2. The application would facilitate the study of the discipline in the classroom. & $3,2 \%$ & $9,8 \%$ & $54,8 \%$ & $29,0 \%$ & $3,2 \%$ \\
\hline 3. The application information is well organized. & $0,0 \%$ & $16,1 \%$ & $45,2 \%$ & $38,7 \%$ & $0,0 \%$ \\
\hline 4. The application has a good graphics / design. & $0,0 \%$ & $9,7 \%$ & $58,0 \%$ & $32,3 \%$ & $0,0 \%$ \\
\hline 5. Can you easily access the content in the application of discipline. & $0,0 \%$ & $6,5 \%$ & $61,3 \%$ & $29,0 \%$ & $3,2 \%$ \\
\hline 6. The application may be useful is to improve their results in discipline & $0,0 \%$ & $3,2 \%$ & $58,1 \%$ & $35,5 \%$ & $3,2 \%$ \\
\hline 7. He recommended the use of the application. & $0,0 \%$ & $9,7 \%$ & $41,9 \%$ & $38,7 \%$ & $9,7 \%$ \\
\hline 8. I wish all teachers would use the application in their respective classes. & $0,0 \%$ & $25,8 \%$ & $19,4 \%$ & $29,0 \%$ & $25,8 \%$ \\
\hline 9. Can you easily access the activities of the application. & $0,0 \%$ & $6,5 \%$ & $61,2 \%$ & $32,3 \%$ & $0,0 \%$ \\
\hline 10. The interaction is given by the application useful. & $3,2 \%$ & $12,9 \%$ & $35,5 \%$ & $45,2 \%$ & $3,2 \%$ \\
\hline
\end{tabular}


Table 7

Usefulness questionnaire results distribution.

\begin{tabular}{|c|c|c|c|c|c|}
\hline $\begin{array}{l}\text { How would you rate the degree of usefulness } \\
\text { of each of the tools of the application? }\end{array}$ & Useless & Somewhat useful & Useful & Very useful & Do not know \\
\hline Questionnaires & $0,0 \%$ & $0,0 \%$ & $71,4 \%$ & $28,6 \%$ & $0,0 \%$ \\
\hline Contents & $0,0 \%$ & $4,8 \%$ & $66,6 \%$ & $28,6 \%$ & $0,0 \%$ \\
\hline Activities & $0,0 \%$ & $4,8 \%$ & $57,1 \%$ & $33,3 \%$ & $4,8 \%$ \\
\hline Videos & $0,0 \%$ & $10,0 \%$ & $35,0 \%$ & $45,0 \%$ & $10,0 \%$ \\
\hline Interaction & $15,0 \%$ & $0,0 \%$ & $50,0 \%$ & $35,0 \%$ & $0,0 \%$ \\
\hline
\end{tabular}

Table 8

Difficulty questionnaire results distribution.

\begin{tabular}{llrr}
\hline $\begin{array}{l}\text { How would you rate the degree of difficulty } \\
\text { in using each of the tools of the application? }\end{array}$ & Difficult & A bit Difficult & Easy \\
\hline Questionnaires & $0,0 \%$ & $4,8 \%$ & $81,0 \%$ \\
Contents & $0,0 \%$ & $4,8 \%$ & $85,7 \%$ \\
Activities & $0,0 \%$ & $0,0 \%$ & $9,5 \%$ \\
Videos & $0,0 \%$ & $5,0 \%$ & $9,5 \%$ \\
\hline
\end{tabular}

The above-mentioned facts indicate that the achieved data can be considered a positive indicator of the Emotion Test Platform adequacy, usability and acceptance by students.

Finally, the results of the assessment questionnaire weren't so positive where Emotion Test platform "I wish all teachers would use the application in their respective classes.". $25,8 \%$ of students disagree with the affirmation and $25,8 \%$ don't have opinion (Table 8). But more than $80 \%$ agree with "The application may be useful is to improve their results in "discipline" and "he recommended the use of the application." This aspect of the platform indicated that the student seems to understand that the platform is more useful out of the classroom.

To assess the usefulness of the application features (questionnaires, contents, activities, videos and interaction) the students was asked how they rate the degree of usefulness of each of them. The next table shows the percentages obtained in the different categories. More than $80 \%$ of the students found that every tools of the application were useful. The functionality "Questionnaire" also obtained the best results; $100 \%$ of students considered the functionality useful.

To assess the difficulty of the application features, the students were asked to rate the degree of difficulty of each tool (questionnaires, contents, activities and videos) of the application.

Table 8 shows the percentages obtained in the different categories. More than $80 \%$ of the students found that every tools of the application were easy to use. These results are in concordance with the Table 6 displayed in regards to the Usefulness of the Platform

The collected evaluation data showed a very high degree of interest and motivation from students resulting from its use. Students also perceived this tool as very relevant for their learning, as a self-operating application to be integrated in a more global learning strategy and self-assessment.

\section{Conclusion}

The research was carried out based on the assumption that emotion can influence several aspects of human life, knowledge acquisition, perception, learning process to the way people communicate and the way rational decisions are made. The main research goal was to find out if the consideration of student's emotional state influences their learning process. Also, if learning results can be improved through the utilization of a learning platform that takes into account the referred student's emotional state. During the course of this work it was attempted to find an answer to this goal.

The collected data from the performed tests showed that there is a statistical difference between students' learning results while using two learning platforms: one learning platform that takes into account the student's emotional state and the other platform that does not take that into consideration. Data analysis provided results that correspond to strong indicators that the adaptability of the platform to the different emotional states, needs and diversity of each student's learning preferences is necessary to achieve greater efficiency and effectiveness in the learning process. Such a conclusion could conceivably be validated with more results in statistical significance if the experiment were carried out with a larger sample and analysis were adjusted for other variables (multivariate analysis).

In this work, in both platforms, the user interface, the learning content and context were adapted to each student, according to his SM (student model), which includes learning and cognitive styles, personality and also emotional state."

"Several research and developed projects using UM (User Modelling) seem to promise good results (Kules, 2000; Martins et al., 2008), but some experimentation and development are still necessary to conclude about the utility of Student Modelling process using learning and cognitive styles and student emotional state to adapt the user interface, learning content and context (Martins et al., 2008). Our project allowed us to define new strategies for the implementation of an Emotional 
learning platform to support and improve the online learning process. The validation of the SM and the solution of an emotional platform seems to be a positive achievement of our research. However, further experiments will be necessary to confirm these results.

In the development of this work other issues became apparent, ones that were beneficial to the research others harmful. The beneficial issue was the use of a new approach in user modelling process that uses learning and cognitive styles and student emotional state to adapt the user interface, learning content and context. This was observed to be very advantageous because the user interface, learning content and context was presented according the student's learning preference and personality and associated with an emotional component enhancing their learning outcomes. Noting that this user modelling process was used in both learning platforms but only one platform used the emotional component.

Two harmful issues were: the time given for testing and the initial difficulty level set in the prototype. Due to participants' schedule restrictions, the initial tests had little time to be conducted, this was observed to be damaging to the research because the students didn't have enough time to complete the test causing frustration and nervousness among them. This issue was corrected in the following tests by giving the students more time to conduct the tests. Another harmful issue was the difficulty level initial set in the prototype. The high level of difficulty triggered some of the students not to complete some of the tasks required to pass to the next level in the prototype causing them to start again, this also led the students to frustration and to give up the conclusion of the test. This was corrected by reducing the level of difficulty in the subsequent tests performed.

With this work one hopes to have contributed to a new approach for an emotional adaptive architecture for online learning that uses the student's emotional state, personality traits and learning preferences to adapt the user interface, learning content and context to the student needs. Also, the contribution of a working prototype that uses the referred architecture that can be adapted to be used in others domains.

In another words, with this research work we have achieved:

- A definition of new strategies for the implementation of learning platform that can support and enhance the learning process;

- A new definition of the Student Model attributes that describe the information, knowledge, learning preferences, personality and emotional profile needed to conduct the learning platform mechanisms;

- Design of an innovative hybrid system that allows relating the representation knowledge, learning preferences, personality and emotions with a learning model and adaptation rules;

- Development of an emotional interaction mechanism able to detect and induce the student's emotional state.

\subsection{Limitations and future work}

The presented research aimed at reaching an understanding on how emotions can impact the students' learning process and despite reaching several interesting conclusions, a set of limitations to the executed experience have been identified and an interesting set of future work activities were also agreed upon.

By analysing the performed experience and the users' interaction with the developed prototype it was possible to perceive that an optimistic approach might have been used and the degree of concern towards the usability and accessibility issues might have been diminished. With this in mind, and assuming the importance which this issue might have on the users' interaction with the prototype (Gonçalves et al., 2014; Martins et al., 2016), an effort is made towards understanding the compliance level of the proposed prototype with the existing accessibility and usability regulations and, if needed error fixing tasks will be implemented.

The current research was performed starting from the assumption that the students who participated in the studies did not have any personal problems, thus discarding any possible influences that these problems might have had on the learning process. Despite this and assuming Manca and Ranieri (2013) arguments on the influence which both temporary and longterm personal problems might have on the learning process, a study on these issues must be performed and updates have to be made to the proposed model in order to have the ability of performing run-time adaptations and mitigate the impact of the referred problems.

When analysing the proposed application model, particularly the subjects' variable, one can notice that only one specific subject was used to perform the initial tests inherent to the present research. Even though the chosen subject was, from our perspective, useful to understand the compliance of our assumptions and proposals, we acknowledge the limitation inherent to this choice. With this in mind, future research must be performed in order to assess the proposed contribution using different learning subjects.

\section{Acknowledgements}

This work is supported by FEDER Funds through the Portuguese "Programa Operacional Factores de Competitividade COMPETE" program and by National Funds through FCT "Fundação para a Ciência e a Tecnologia" under the project: FCO MP-01-0124-FEDER-PEst-OE/EEI/UI0760/2014. 


\section{References}

Busato, V., Prins, F., Elshout, J., Hamaker, C., 1998. The relation between learning styles, the Big Five personality traits and achievement motivation in higher education. Pers. Individ. Dif. 26, 129-140.

Clark, J., van Oorschot, P., 2013. SoK: SSL and HTTPS: Revisiting past challenges and evaluating certificate trust model enhancements. Security and Privacy (SP). IEEE Symposium on, IEEE, pp. 511-525.

Coelho, V., Sousa, V., Figueira, A., 2014. The Impact of a School-Based Social and Emotional Learning Program on the Self-Concept of Middle School Students//O impacto de um programa escolar de Aprendizagem Socioemocional sobre o autoconceito de alunos de $3^{\circ}$ ciclo. J. Psychodidactics, 19.

Diseth, Å., 2003. Personality and approaches to learning as predictors of academic achievement European. J. Pers. 17, $143-155$.

Faria, R., Almeida, A., Martins, C., Gonçalves, R., 2015a. Emotional Adaptive Platform for Learning. Methodologies and Intelligent Systems for Technology Enhanced Learning. Springer, pp. 9-16.

Faria, R., Almeida, A., Martins, C., Gonçalves, R., Figueiredo, L., 2015b. Including Emotion in Learning Process. Portuguese Conference on Artificial Intelligence. Springer, pp. 27-32.

Felder, R., Silverman, L., 1988. v. Eng. Educ. 78, 674-681.

Fleming, N., Baume, D., 2006. Learning Styles Again: VARKing up the right tree! Educ. Dev. 7, 4.

Garcia, D., 2012. The affective temperaments: differences between adolescents in the big five model and Cloninger's psychobiological model of personality. J. Happiness Stud. 13, 999-1017.

Gonçalves, R., Martins, J., Branco, F., 2014. A Review on the Portuguese Enterprises Web Accessibility Levels-A website accessibility high level improvement proposal. Proc. Comput. Sci. 27, 176-185.

Gosling, S., Rentfrow, P., Swann, W., 2003. A very brief measure of the Big-Five personality domains. J. Res. Pers. 37, 504-528.

Ibrahimoglu, N., Unaldi, I., Samancioglu, M., Baglibel, M., 2013. The relationship between personality traits and learning styles: a cluster analysis. Asian J. Manage. Sci. Educ., 93-108

Javanbakht, A., Duval, E., Cisneros, M., Taylor, S., Kessler, D., Liberzon, I., 2016. Instructed fear learning, extinction, and recall: additive effects of cognitive information on emotional learning of fear. Cogn. Emot., 1-8

Khurana, I., 2014. Textbook of Human Physiology for Dental Students. Elsevier Health Sciences.

Kobsa, A., 1993. User modeling: recent work, prospects and hazards. Hum. Factors Inf. Technol. 10, 111-111..

Kolb, D., 2014. Experiential Learning: Experience as the Source of Learning and Development. FT press.

Komarraju, M., Karau, S., Schmeck, R., 2009. Role of the Big Five personality traits in predicting college students' academic motivation and achievement. Learn. Individ. Dif. 19, 47-52.

Komarraju, M., Karau, S., Schmeck, R., Avdic, A., 2011. The Big Five personality traits, learning styles, and academic achievement. Pers. Individ. Dif. 51, 472477.

Kort B., Reilly R., Picard R., 2001. An Affective Model of Interplay between Emotions and Learning: Reengineering Educational Pedagogy-Building a Learning Companion. icalt, pp. 43-47.

Kules, B., 2000. User modeling for adaptive and adaptable software systems. ACM Conference on Universal Usability, pp. $16-17$.

Kumar, K., Bakhshi, A., Rani, E., 2009. Linking the'Big Five' personality domains to Organizational citizenship behavior. Int. J. Psychol. Stud. 1, 73.

Li, L., Cheng, L., Qian, K., 2008. An e-learning system model based on affective computing. Cyberworlds. International Conference on, IEEE, pp. 45-50.

Manca, S., Ranieri, M., 2013. Is it a tool suitable for learning? A critical review of the literature on Facebook as a technology-enhanced learning environment. J. Comput. Assisted Learn. 29, 487-504.

Martins, A., 2012. Sistemas Hipermédia Adaptativa Para Suporte De Ambientes De Aprendizagem Construtivistas. Universidade do Porto.

Martins, C., Faria, L., Carvalho, C., Carrapatoso, E., 2008. User modeling in adaptive hypermedia educational systems. Educ. Technol. Soc. 11, 194-207.

Martins, J., Gonçalves, R., Branco, F., Pereira, J., Peixoto, C., Rocha, T., 2016. How Ill Is Online Health Care? An Overview on the Iberia Peninsula Health Care Institutions Websites Accessibility Levels. In: Rocha, Á., Correia, M.A., Adeli, H., Reis, P.L., Mendonça Teixeira, M. (Eds.), New Advances in Information Systems and Technologies, vol. 2. Springer International Publishing, Cham, pp. 391-400.

Molleman, E., 2005. Diversity in demographic characteristics, abilities and personality traits: do faultlines affect team functioning? Group Decis. Negot. 14, $173-193$.

Morgan, R., Baker, F., 2012. A Comparison of VARK Analysis Studies and Recommendations for Teacher Educators Ron Morgan and Fred Baker. University of South Alabama, Alabama.

Orbe.us. ReKognition - Welcome to Rekognition.com. 2015.

Robins, R., Trzesniewski, K., 2005. Self-esteem development across the lifespan. Curr. Directions Psychol. Sci. 14, 158-162.

Rothmann, S., Coetzer, E., 2003. The big five personality dimensions and job performance. SA J. Ind. Psychol. 29.

Santos, R., 2010. Sistema de Apoio à Argumentação em Grupo em Ambientes Inteligentes e Ubíquos considerando Aspectos Emocionais e de Personalidade. Universidade de Trás-os-Montes e Alto Douro.

Saucier, G., Srivastava, S., 2015. What makes a good structural model of personality? Evaluating the Big Five and alternatives. In: Handbook of Personality and Social Psychology, vol. 3, pp. 283-305.

Shaver, P., Schwartz, J., Kirson, D., O'connor, C., 1987. Emotion knowledge: further exploration of a prototype approach. J. Pers. Soc. Psychol. 52, 1061.

Shen, L., Wang, M., Shen, R., 2009. Affective e-learning: using“ emotional” data to improve learning in pervasive learning environment. Educ. Technol. Soc. $12,176-189$

Shiota, M., Keltner, D., John, O., 2006. Positive emotion dispositions differentially associated with Big Five personality and attachment style. J. Positive Psychol. 1, 61-71.

Stafford T., 2004. What good are positive emotions?, British Psychological Soc ST Andrews House, 48 Princess RD East, Leicester LE1 7DR, LEICS, England.

Um, E., Song, H., Plass, J., 2007. The effect of positive emotions on multimedia learning. In: Proceedings of world conference on educational multimedia, hypermedia and telecommunications. AACE Chesapeake, VA, pp. 4176-4185.

Willingham, D., Hughes, E., Dobolyi, D., 2015. The Scientific Status of Learning Styles Theories. Teach. Psychol. 42, 266-271.

Woodward, C., Chambers, L., 1983. Guide to Questionnaire Construction and Question Writing. Canadian Public Health Association. 